\title{
Persepsi Mahasiswa pada Penuntun Praktikum Fisika Dasar II Berbasis Mobile Learning
}

\author{
Darmaji $^{1}$, Dwi Agus Kurniawan ${ }^{1}$, Astalini $^{1}$, Neng Ria Nasih ${ }^{1}$ \\ ${ }^{1}$ Pendidikan Fisika-Universitas Jambi
}

\section{INFO ARTIKEL}

\section{Riwayat Artikel:}

Diterima: 21-03-2019

Disetujui: 22-04-2019

\section{Kata kunci:}

preception;

practicum guide;

mobile learning;

persepsi;

penuntun praktikum;

mobile learning

\author{
Alamat Korespondensi: \\ Darmaji \\ Pendidikan Fisika \\ Universitas Jambi \\ Jalan Lintas Jambi Muara Bulian Km 15, Mendalo Darat Jambi \\ E-mail: darmaji@unja.ac.id
}

\begin{abstract}
This research aims to see the perceptions of students in the Basic Physics II practical guide based on mobile learning. The study used quantitative methods with descriptive analysis. The instruments used were perception questionnaires and interview sheets. The results of the perceptions of students in the biology education study program are categorized as good with a percentage of $58.62 \%$ and in the mathematics education study program it is categorized as good with a percentage of $50 \%$. From the data, it is known that the basic learning practice guide II based on mobile learning can support the learning process and practicum.
\end{abstract}

\begin{abstract}
Abstrak: Penelitian ini bertujuan untuk melihat persepsi mahasiswa pada penuntun praktikum Fisika Dasar II berbasis mobile learning. Penelitian menggunakan metode kuantitatif dengan analisis deskriptif. Instrumen yang digunakan berupa angket persepsi dan lembar wawancara. Hasil persepsi mahasiswa pada program studi pendidikan biologi dikategorikan baik dengan persentase sebesar $58.62 \%$ dan pada program studi pendidikan matematika dikategorikan baik dengan persentase sebesar $50 \%$. Dari data diketahui bahwa penuntun praktikum fisika dasar II berbasis mobile learning dapat mendukung proses pembelajaran dan praktikum.
\end{abstract}

Fisika merupakan pembelajaran dengan ilmu pengetahuan yang membahas gejala-gejala dan sifat-sifat pada benda yang beradadi alam. Physics is part of the science that has the nature of a process, product, and values (Edie et al., 2018). The physics education study program is one of the study programs which is available in a faculty of teacher and education which has the aim to produce skilled graduates in various aspects of competence such as knowledge, understanding, and skill (Kurniawan \& Parasdila, 2018). Pembelajaran Fisika sangat begitu penting untuk dipelajarai karena pembelajaran fisika adalah suatu pembelajaran yang paling dasar. Menurut Young, dkk (2002), terdapat dua alasan kita harus belajar fisika yaitu (1) salah satu ilmu pengetahuan paling dasar merupakan ilmu fisika dan (2) semua ilmu teknologi dan ilmu rekayasa merupakan dasar dari pembelajaran. Dalam aktivitas untuk menyelesaikan suatu permasalahan mampu dilakukan dengan memebimbing siswa untuk menunjukkan pengetahuan yang dimilikinya, hal ini adalah salah satu dari tujuan untuk pembelajaran fisika (Maksum, Maliki, \& Hidayat, 2017). Mata kuliah pelajaran fisika umum salah satunya Fisika Dasar II. Fisika dasar II merupakan salah satu mata pelajaran Fisika wajib yang berada di program studi pendidikan Fisika Universitas Jambi. Pelajaran Fisika tergolong dalam kategori pelajaran yang sulit. Transferable skills can be developed through science learning process in classrooms or practicum in laboratories (Setiawan, Malik, Suhandi, \& Permanasari, 2018). Dengan demikian, untuk mempermudah mahasiswa dalam memahami pembelajaran fisika dibutuhkan praktikum Fisika Dasar II.

Praktikum Fisika Dasar II bertujuan untuk membantu mahasiswa memecahkan masalah fenomena alam dan melatih keterampilan proses sains mahasiswa. Practicum is a one of teaching that aims to propose students execute and test real what is obtained in theory (Kustijono, 2018). From the observation found that students in the experimental class more active during the learning process (Supurwoko et al., 2018). Agar praktikum yang dilakukan akan berjalan dengan sempurna maka dibutuhkan penuntun praktikum mudah dan jelas untuk dipahami. Penuntun praktikum dalam kategori yang baik tentu akan dipahami oleh mahasiswa dengan mudah. Penuntun praktikum dalam Fisika Dasar II yang digunakan saat ini adalah penuntun praktikum yang mampu melatih keterampilan proses sains mahasiswa. Keterampilan proses sains yang dimiliki mahasiswa dapat dikembangkan melalui praktikum yang menggunakan penuntun praktikum yang mampu melatih keterampilan proses sains. Kegiatan praktikum membutuhkan keterampilan proses sains yang dimiliki mahasiswa, seperti merumuskan hipotesis; merumuskan masalah; definisi operasional variabel; mengidentifikasi variabel dan menganalisis data; serta menarik kesimpulan sehingga menemukan ilmu pengetahuan dalam mencapai kompetensi pembelajaran (Misbah, Wati, Rif'at, \& Prastika, 2018). In explaining the level of scientific creativity students can identify problems, observe, set hypotheses, conclude, identify variables, 
choose methods, control variables, identify variables, and make conclusions that can train students' scientific process skills. Some studies find this relationship between SPS and SC (Ozdemir \& Dikici, 2016). Keterampilan proses sains begitu sangat dibutuhkan dalam aktivitas suatu pembelajaran dan praktikum guna membantu mahasiswa dalam memahami konsep-konsep pembelajaran. Keterampilan yang sangat begitu penting dalam pendidikan untuk dikembangkan khususnya pada praktikum adalah keterampilan proses sains mahasiswa (Rahmawati, Handayanto, Dasna, 2018). Keterampilan proses sains begitu sangat dituntut untuk mahasiswa dalam meningkatkan proses pembelajaran (Hartini, Ibrohim, \& Qohar, 2018). Karena keterampilan proses sains serta penguasaan konsep adalah sesuatu yang sangat begitu penting dimiliki, maka masalah yang timbul dalam keterampilan proses sains dan penguasaan konsep yang dialami oleh mahasiswa ini harus ditangani dengan segera mungkin oleh seorang dosen fisika, (Yadaeni, Kusairi, \& Parno, 2018). Penggunaan penuntun praktikum yang mampu melatih keterampilan proses sains mahasiswa sangat membantu dalam proses pelaksanaan praktikum berlangsung khususnya dalam melatih keterampilan proses sains mahasiswa tersebut.

Selain melatih keterampilan proses sains pada mahasiswa maka penggunaan penuntun praktikum, persepsi mahasiswa terhadap media yang digunakan menyatakan bahwa mampu membantu mahasiswa dalam kegiatan pembelajaran. Suatu media dan modul praktikum dapat membantu keterbatasan dalam pelaksanaan praktikum sehingga mahasiswa mendapatkan pengalaman belajarnya ( Limatahu, et al., 2017). Media is one channel of communication, derived from the Latin word meaning "between," this term means that to anyone who carries information (Heinich, Molenda,\& Russell,2002). Media merupakan model-model dari komunikasi baik dalam bentuk tercetak maupun dalam bentuk audiovisual dan peralatannya (Sadiman, Raharjo, Haryono, \& Harjito, 2014). Media yang mampu memberikan informasi dengan tepat antara penerima informasi dan pemberi informasi merupakan media yang baik (Pratama, Ulfa, \& Kuswandi, 2013). Dengan terdapatnya media suatu pembelajaran maka dapat memotivasi proses pembelajaran sehingga hal ini akan mempermudah baik pendidik maupun peserta didik. Dalam aktivitas belajar dan pembelajaran maka akan memberikan dampak yang positif pada siswa ketika pelaksanaan pembelajaran berlangsung sehingga dibutuhkan media suatu pembelajaran untuk memudahkan pendidik (Zulika, Wijaya, Masitoh, Utari, \& Titin, 2018). Semangkin berkembangnya zaman maka baik dalam bidang media teknologi maupun media pembelajarann yang digunakan pada pembelajaran juga semangkin berkembang. Past few decades, human have experienced a revolution in the computer sciences, not only in terms of its ability but also in terms of its use (Based, Knowledge, Ta, Abed, \& Ahmad, 2017). Dengan begitu media teknologi sangat mendukung aktivitas pembelajaran.

Sejalan dengan revolusi industri 4.0 maka berbagai teknologi telah semakin berkembang sangat begitu pesat. Pemanfaatan teknologi dalam aktivitas pembelajaran pada era yang modern saat ini banyak dimana-mana, salah satunya media pembelajaran berbasis smartphone. Teknologi pada era yang modern ini banyak digunakan sebagaia media pada pembelajaran dengan itu hal tersebut sangat mendukung aktivitas pembelajaran. Dalam suatu pendidikan, biasanya memanfaatkan teknologi informasi yang dilakukan guna untuk meningkatkan pada kualitas suatu pembelajaran sehingga mampu meningkatkan kualitas pada pendidikan (Prasojo \& Riyanto, 2011). Over the last few decades information and communication technologies have improved greatly and the use of computers has become more widespread (Vyas \& Nirban, 2014). Melalui berbagai keunggunlan dalam penggunaan teknologi yang dimiliki, salah satunya adalah teknologi computer telah menginspirasi banyak ahli di bidang pendidikan untuk memberdayakannya dalam skala yang lebih luas, sehingga untuk proses penggunaannya tidak terbatas dalam pembelajaran semata, tetapi juga menjadi peranti utama untuk mengimplementasikan pendidikan (Prawiradilaga, Ariani, \& Handoko, 2013). The concept of Industry 4.0 assumes blurring the differences between the work of people and the work of machines (Ślusarczyk, 2019). Media dalam pembelajaran dengan penggunaan teknologi tidak terdengar asing lagi pada masa ini. Dengan itu peneliti ingin melihat persepsi mahasiswa terhadap penuntun praktikum Fisika Dasar II berbasis mobile learning.

Persepsi merupakan suatu proses mahasiswa mengartikan, mengevaluasi, menerima, memberi pendapat, dan menguji kepada data dan respons panca indra pada apa yang dilihat. Dalam menggunakan panca indra yaitu seperti melihat begitu erat terkait dengan persepsi mahasiswa setelah objek yang bersangkutan melihat. Persepsi mahasiswa biasanya terjadi ketika saat aktivitas pembelajaran di kelas baik persepsi terhadap materi pembelajaran, teknik pembelajaran yang digunakan maupun media yang digunakan. Pengaruh terhadap lingkungan sosial dimana individu tersebut tinggal dapat menyebabkan persepsi sesorang timbul (Fitriana, Utaya, \& Budijanto 2016). Several studies have shown that $m$-learning applications can facilitate students in various ways; e.g., by creating ease in learning content and interacting with others, anytime and anywhere (Cahyanti, Sinaga, \& Amsor, 2018). Penggunaan mobile learning mampu untuk membantu mahasiswa dengan menggunakan alat seluler atau strategi pembelajaran untuk mencapai tujuan yang telah ditetapkan. researchers and relevant instructors need to pay more attention to how to effectively make use of mobile tools or learning strategies to attain good learning effects, or what kind of mobile learning in physical education will be the development trend in the future (Yang, Hwang, \& Sung, 2018).

Pada penuntun praktikum Fisika Dasar II yang digunakan saat ini berbasis hard copy. Penggunaan penuntun praktikum berbasis hard copy tersebut begitu kurang efektif dan efisien maka untuk mempermudah hal tersebut dapat digunakan media sebagai pendukung proses pembelajaran. Selain itu, terdapat pemborosan dalam penggunaan kertas dan sulit jika dibawa kemana-mana. Menurut Mehdipour \& Zerehkahfi (2013), bahwa pembelajaran ketika saat menggunakan media berbasis mobile 
learning muncul sebagai suatu solusi terhadap tantangan yang akan dihadapi pendidikan dengan berbagai sumber daya dan alat pembelajaran serta dapat memberikan tingkatan untuk personalia pembelajaran. Selanjutnya, untuk meminimalisir penggunaan kertas dan agar pemebelajaran atau praktikum berjalan dengan efisien dan efektif maka solusinya dengan penggunaan penuntun praktikum Fisika Dasar II berbasis mobile learning. Dengan penggunaan penuntun praktikum Fisika Dasar II berbasis mobile learning maka dapat digunakan untuk dimanapun dan kapanpun. Dengan demikian, dalam mempermudah dalam pelaksanaan praktikum dan agar menambah wawasan mahasiswa peneliti mempertimbangkan untuk melihat persepsi mahasiswa pada penuntun praktikum Fisika Dasar II berbasis mobile learning. Penelitian yang dilakukan bertujuan untuk melihat persepsi mahasiswa pada penuntun praktikum Fisika Dasar II berbasis mobile learning.

\section{METODE}

Penelitian ini yang dilakukan merupakan penelitian yang menggunakan teknik deskriptif kuantitatif dengan menggunakan variabel penelitian persepsi tentang penggunaan penuntun praktikum fisika dasar II berbasis mobile learning. Penelitian statistik deskriptif mengarah kepada menafsirkan dan memahami arti dari data atau angka yang dihasilkan dengan menggunakan data mentah dan ditransformasikan pada suatu bentuk (Sarwono, 2006). Angket persepsi mahasiswa yang digunakan terdiri dari 20 pernyataan dan untuk lembar wawancara terdiri dari 20 pertanyaan. Responden terdiri dari 58 mahasiswa. Pengumpulan data untuk persepsi mahasiswa terhadap penggunaan penuntun praktikum fisika dasar II berbasis mobile learning yaitu dengan menggunakan skala likert.

Teknik yang digunakan untuk penelitian ini yaitu dengan menggunakan angket persepsi mahasiswa dan lembar wawancara terhadap penuntun praktikum fisika dasar II berbasis mobile learning. Untuk mengukur angket persepsi mahasiswa yaitu dengan mempergunakan teknik skala likert dalam lima pilihan jawaban. Pilihan jawaban pada angket persepsi terdiri dari pemberian skor untuk butir pernyataan negatif dan positif. Untuk pemberian skor pada butir pernyataan positif yaitu selalu $(S L)=5$, sering $(S R)=4$, kadang-kadang $(K K)=3$, jarang $(J R)=2$, dan tidak pernah $(T P)=1$. Untuk pemberian skor pada butir pernyataan negative yaitu selalu $(\mathrm{SL})=1$, sering $(\mathrm{SR})=2$, kadang-kadang $(\mathrm{KK})=3$, jarang $(\mathrm{JR})=4$, dan tidak pernah $(\mathrm{TP})=5$. Level persepsi mahasiswa pada penuntun praktikum fisika dasar II berbasis mobile learning dapat dilihat pada tabel 1.

Tabel 1. Level Persepsi Mahasiswa Pada Penuntun Praktikum Fisika Dasar II Berbasis Mobile Learning

\begin{tabular}{cll}
\hline No & Interval Skor & Level Persepsi Mahasiswa \\
\hline 1 & $20.0-36.0$ & Sangat Tidak Baik \\
\hline 2 & $36.1-52.0$ & Tidak Baik \\
\hline 3 & $52.1-68.0$ & Cukup \\
\hline 4 & $68.1-84.0$ & Baik \\
\hline 5 & $84.1-100$ & Sangat Baik \\
\hline
\end{tabular}

Tabel 1 menunjukkan level persepsi mahasiswa yang digunakan untuk menentukan level dari masing-masing persepsi mahasiswa yang dapat dikategorikan Sangat Baik, Baik, Cukup, Baik, dan Sangat Baik sesuai dengan interval skor yang dihasilkan. Dengan menggunakan deskriptif kuantitatif maka akan dihasilkan Modus, Median, Mean, Range, dan standar deviasi (SD), rentang pada nilai minimum dan rentang pada nilai maksimum untuk setiap variabel. Berdasarkan hasil yang didapatkan dibuat tabel untuk distribusi frekuensi. Dalam mengolah data untuk mendapatkan hasil tersebut yaitu dengan menggunakan bantuan SPSS 24.

HASIL

Hasil dari data persepsi mahasiswa dengan menggunakan angket persepsi pada program studi pendidikan Matematika dan Biologi yang sedang melaksanakan praktikum fisika dasar II terhadap penuntun praktikum fisika dasar II berbasis mobile learning dapat dilihat pada tabel 2.

Tabel 2. Deskripsi Statistik Persepsi Program Studi Matematika

\begin{tabular}{|c|c|c|}
\hline \multirow[t]{2}{*}{$\mathbf{N}$} & Valid & 28 \\
\hline \multirow{2}{*}{\multicolumn{2}{|c|}{$\begin{array}{ll} & \text { Missing } \\
\text { Mean } & \end{array}$}} & 0 \\
\hline & & 68,3214 \\
\hline \multicolumn{2}{|c|}{ Std. Error of Mean } & 1,73591 \\
\hline \multicolumn{2}{|c|}{ Median } & 69,0000 \\
\hline \multicolumn{2}{|c|}{ Mode } & 69,00 \\
\hline \multicolumn{2}{|c|}{ Std. Deviation } & 9,18555 \\
\hline \multicolumn{2}{|c|}{ Range } & 47,00 \\
\hline \multicolumn{2}{|c|}{ Minimum } & 42,00 \\
\hline
\end{tabular}


Maximum 89,00

Berdasarkan tabel 2 mengenai deskripsi statistik persepsi program studi pendidikan Matematika pada penuntun praktikum fisika dasar II berbasis mobile learning menunjukkan bahwa untuk perolehan skor angka dari 28 responden dengan menghasilkan data yang valid untuk nilai minimumnya adalah 42,00 dan nilai maksimum 89,00 dengan rata-rata 68,3214, median 69,0000, modus 69,00 dan dengan standar deviasi 9,18555.

Untuk menunjukkan persepsi mahasiswa termasuk pada kategori Sangat Baik, Baik, Cukup, Tidak Baik, dan Sangat Tidak Baik maka dibutuhkan skor interval dalam membedakannya. Untuk level atau tingkat persepsi mahasiswa program studi pendidikan Matematika terdiri dari 28 responden dapat dilihat pada tabel 3.

Tabel 3. Tabel Indeks Level Persepsi Program Studi Matematika

\begin{tabular}{ccccc}
\hline No & Interval Skor & Level Persepsi Mahasiswa & F & $(\boldsymbol{\%})$ \\
\hline 1 & $20.0-36.0$ & Sangat Tidak Baik & 0 & 0 \\
2 & $36.1-52.0$ & Tidak Baik & 1 & 3.5 \\
3 & $52.1-68.0$ & Cukup & 12 & 42.85 \\
4 & $68.1-84.0$ & Baik & 14 & 50 \\
5 & $84.1-100$ & Sangat Baik & 1 & 3.5 \\
\hline & Jumlah & & $\mathbf{2 8}$ & $\mathbf{1 0 0}$ \\
\hline
\end{tabular}

Pada tabel 3 menunjukkan hasil dari level persepsi program studi matematika. Level persepsi program studi Matematika termasuk dalam kategori baik dengan frekuensi 14 dan persentase sebesar $50 \%$.

Tabel 4. Deskripsi Statistik Persepsi Program Studi Biologi

\begin{tabular}{lcc}
\hline $\mathbf{N}$ & Valid & 29 \\
\cline { 2 - 3 } & Missing & 0 \\
\hline Mean & 78,3793 \\
Std. Error of Mean & 1,85457 \\
Median & 78,0000 \\
Mode & 78,00 \\
Std. Deviation & 9,98718 \\
Range & 43,00 \\
Minimum & 57,00 \\
Maximum & 100,00 \\
\hline
\end{tabular}

Berdasarkan tabel 4 mengenai deskripsi Statistik Persepsi Program Studi Pendidikan Biologi menunjukkan bahwa untuk perolehan skor angka dari 29 responden dengan menghasilkan data yang valid untuk persepsi mahasiswa dengan nilai minimumnya 57,00 dan nilai maksimum 100,00 dengan rata-rata 78,3793, median 78,0000, modus 78,00 dengan standar deviasi 9,98718. Untuk level atau tingkat persepsi mahasiswa program studi pendidikan Biologi yang terdiri dari 29 responden dapat dilihat pada tabel 5 .

Tabel 5. Tabel Indeks Level Persepsi Persepsi Program Studi Biologi

\begin{tabular}{ccccc}
\hline No & Interval Skor & Level Persepsi Mahasiswa & F & $(\boldsymbol{\%})$ \\
\hline 1 & $20.0-36.0$ & Sangat Tidak Baik & 0 & 0 \\
2 & $36.1-52.0$ & Tidak Baik & 0 & 0 \\
3 & $52.1-68.0$ & Cukup & 5 & 17.24 \\
4 & $68.1-84.0$ & Baik & 17 & 58.62 \\
5 & $84.1-100$ & Sangat Baik & 7 & 24.13 \\
\hline \multicolumn{2}{c}{ Jumlah } & & $\mathbf{2 9}$ & $\mathbf{1 0 0}$ \\
\hline
\end{tabular}

Tabel 5 mengenai Indeks Level persepsi program studi pendidikan biologi pada penuntun praktikum fisika dasar II berbasis mobile learning termasuk dalam kategori baik yang mana terdapat pada frekuensi 17 mahasiswa dengan persentase sebesar 58.62\%. Berdasarkan hasil dari data di atas menampilkan bahwa terdapat respon positif dari mahasiswa pendidikan Biologi pada penuntun praktikum fisika dasar II berbasis mobile learning. 


\section{PEMBAHASAN}

Hasil data dari persepsi program studi pendidikan Matematika dan program studi pendidikan Biologi pada penuntun praktikum fisika dasar II berbasis mobile learning dihasilkan persepsi yang berbeda antara nilai dari rata-rata, median, modus, standar deviation, nilai minimum, dan nilai maksimum. Persepsi mahasiswa program studi pendidikan Biologi dengan persepsi mahasiswa program studi pendidikan Matematika termasuk dalam kategori baik. Sehingga dapat dilihat dari hasil masingmasing untuk persepsi program studi pendidikan Biologi nilai minimumnya adalah 57,00 dan nilai maksimum 100,00 dengan rata-rata 78,3793, median 78,0000, modus 78,00 dan dengan standar deviasi 9,98718. Untuk indeks level persepsi pada program studi pendidikan Biologi frekuensi sebanyak 17 mahasiswa dengan persentase sebesar 58.62\%. Hasil dari data angket persepsi menunjukkan bahwa respon mahasiswa pendidkan Biologi dalam kategori baik yang berarti penggunaan penuntun praktikum fisika dasar II berbasis mobile learning dapat mendukung kegiatan pembelajaran yang dapat diakses dimapun dan kapanpun. Sejalan dengan penelitia yang dilakukan oleh (Adel Ali \& Rafie Mohd Arshad, 2017), students support the idea of utilizing mobile learning in their studies because it helps them to access different resources at anytime and anywhere to gain knowledge so as to increase flexibility in learning. Sehingga dinyatakan bahwa begitu fleksibilitas suatu pembelajaran dengan melalui penggunaan media berbasis mobile learning. Dengan penggunaan penuntun praktikum berbasis mobile learning dapat mempermudah mahasiswa dalam kegiatan praktikum. Mahasiswa juga dapat menggunakan penuntun praktikum dimanapun dan kapanpun.

Untuk hasil persepsi mahasiswa program studi pendidikan matematika nilai minimumnya adalah 42,00 dan nilai maksimum 98,00 dengan rata-rata 73.1786, median 74,5000, modus 69,00 dan dengan standar deviasi 11,56641. Selanjutnya untuk program studi pendidikan Matematika frekuensi sebanyak 14 mahasiswa dengan persentase sebesar 50\%. Dari data yang dihasilkan menunjukkan bahwa terdapat respon positif dari pendidikan matematika yang berarti bahwa dengan menggunakan penuntun praktikum fisika dasar II berbasis mobile learning dapat mendukung kegiatan pembelajaran dan praktikum dapat dilakukan lebih fleksibilitas. Menurut Delialioğlu \& Alioon (2014), The result indicated that computers were satisfied by some of the m-learning applications such as e-book, they looked for more flexible applications that can enable them to perform more regular tasks such as taking notes or editing options while studying. Hasil persepsi mahasiswa dengan menggunakan angket persepsi menyatakan bahwa dengan penggunaan penuntun praktikum fisika dasar II berbasis mobile learning menghasilkan respon yang positif. Karena dengan penggunaan media pembelajaran barbasis mobile learning lebih meningkatkan motivasi mahasiswa dalam pelaksanaan praktikum.

Untuk lembar wawancara yang digunakan dalam penelitian ini menggunakan 20 pertanyaan dengan 9 responden. Dengan lima responden program studi pendidikan Matematika dan empat responden program studi pendidikan Biologi. Berikut beberapa pertanyaan dan hasil wawancara yang mewakili dari mahasiswa program studi pendidikan Matematika dan Biologi yaitu

1. Apakah penggunaan smartphone dalam pembelajaran adalah ide yang bagus?

○ Ya

○ Tidak

Berikan alasan Anda:

2. Apakah Anda setuju bahwa penggunaan smartphone membantu Anda belajar kapanpun dan dimanapun?

$\circ$ Ya

○ Tidak

Berikan alasan Anda:

3. Apakah pembelajaran melalui smartphone meningkatkan motivasi belajar Anda?

$\circ \mathrm{Ya}$

○ Tidak

Berikan alasan Anda:

Berdasarkan hasil wawancara yang dihasilkan termasuk dalam kategori baik karena respon dari mahasiswa rata-rata menjawab pilihan positif untuk lembar wawancara yang disertai dengan alasan. Alasan yang diberikan kepada berbagai mahasiswa berbeda-beda salah satunya pada program studi pendidikan matematika adalah "Apakah penggunaan smartphone dalam pembelajaran adalah ide yang bagus?" Jawabannya yaitu Ya, dengan alasan "karena mudah dibawa kemana-mana". Berdasarkan alasan yang disampaikan dapat dinyatakan bahwa penggunaan smartphone dalam pembelajaran sangat membantu dalam penggunaannya dan mudah untuk dibawa kemana-mana karena smartphone lebih praktis. Untuk program studi pendidikan Biologi alasannya adalah "Pembelajaran akan lebih bervariasi". Alasan yang disampaikan mengartikan bahwa dengan menggunakan smartphone dapat memberi dukungan pada kegiatan pembelajaran dan memberikan informasi bahwa dengan menggunakan smartphone merupakan ide yang bagus untuk proses pembelajaran dan praktikum akan lebih bervariasi. 
Sesuai dengan penelitian yang dilakukan oleh Maksum et al. (2017) menyatakan bahwa penelitian yang dilakukan dengan menghasilkan bahwa smartphone dapat digunakan sesuai tingkat pemahaman siswa dimana siswa bebas memilih materi sesuai dengan kebutuhannya. Kebutuhan dalam kegiatan pembelajaran salah satunya adalah dengan media yang dapat digunakan secara praktis, seperti smartphone. Dengan seperti itu, mahasiswa yang mengalami keterlambatan belajar dapat mengejar ketinggalannya dengan mengakses materi yang dia belum kuasai. Untuk pertanyaan selanjutnya "Apakah Anda setuju bahwa penggunaan smartphone membantu Anda belajar kapanpun dan dimanapun?" Jawaban dari mahasiswa yaitu Ya, dengan alasan "karena disaat kita sedang hangout bersama teman, kita masih tetap bisa mencari media yang kita inginkan tanpa harus repot mengeluarkan laporan dan mencari sambungan internet". Berdasarkan jawaban dan alasan yang disampaikan dapat diartikan bahwa dengan penggunaan smartphone membantu mahasiswa belajar kapanpun dan dimanapun. Pertanyaan selanjutnya "Apakah pembelajaran melalui smartphone meningkatkan motivasi belajar Anda?" Jawaban dari mahasiswa yaitu Ya, dengan alasan "Semakin banyak hal yng baru kita ketahui". Berdasarkan jawaban dan alasan yang disampaikan menyatakan bahwa penggunaan smartphone dapat meningkatkan motivasi belajar mahasiswa yang mana semangkin banyak mendapatkan pengetahuan yang baru. In the classroom, the use of mobile devices has been found to contribute to the learning experience and engage students during lectures. Students perceive the tablet PC to be effective in improving their learning environment (Foti \& Mendez, 2014).

Data dari wawancara program studi pendidikan Matematika sebanyak lima mahasiswa dan program studi pendidikan Biologi sebanyak empat mahasiswa. Dalam penggunaan lembar wawancara selain menggunakan jawaban "ya" dan "tidak", lembar wawancara juga menggunakan jawaban selalu, sering, kadang-kadang dan tidak pernah. Hasil wawancara program studi pendidikan Matematika menyatakan bahwa terdapat sebagian besar mahasiswa menyatakan sering dalam pertanyaan dari wawancara. Hasil wawancara memberikan data bahwa terdapat respon yang positif dari mahasiswa pendidikan matematika. Menurut Vyas \& Nirban (2014), responses to the first question regarding the definition of mobile learning, show a good level of awareness among students as 59\% of the respondents said that it is learning using portable devices. Salah satu pertanyaan pada lembar wawancara yang menggunakan jawaban selalu, sering, kadang-kadang dan tidak pernah adalah "Apakah Anda sering menggunakan smartphone?" jawaban mahasiswa sebagian besar menjawab selalu. Dengan alasan "Karena semua kebutuhan sudah bisa diakses melalui smartphone". Berdasarkan jawaban tersebut maka dapat dinyatakan bahwa mahasiswa selalu menggunakan smartphone dalam kehidupan sehari-hari karena melalui smartphone semua kebutuhan dapat terpenuhi dengan hanya mengakses melalui smartphone. Sejalan pada penelitian yang dilakukan oleh Al-Hajri, Al-Sharhan, \& Al-Hunaiyyan (2017), Mobile learning is a suitable and effective choice in the world because the penetration of mobile devices is widespread among young students.

Data hasil wawancara program studi pendidikan Biologi sebanyak empat mahasiswa menghasilkan respon yang positif. Untuk salah satu pertanyaan pada lembar wawancara yang menggunakan jawaban selalu, sering, kadang-kadang dan tidak pernah adalah "Apakah Anda sering menggunakan smartphone?" jawaban mahasiswa adalah selalu. Dengan alasan bahwa penggunaan smartphone dalam proses pembelajaran akan lebih mempermudah kegiatan praktikum yang lebih praktis. Aspek keterampilan proses sangatlah dibutuhkan dalam penuntun praktikum pada setiap langkah kegiatan praktikum yang seharusnya berada pada penuntun praktikum (Darmaji, Astalini, Rahayu \& Maison, 2018). Basic Physics II practicum guide based on science process skills on, effectively used to improve science process skills of observation, measuring, predicting, identifying variables, planning experiments, and conducting experiments (Darmaji, Kurniawan, \& Suryani, 2019). Berdasarkan jawaban mahasiswa tersebut dapat dinyatakan, mahasiswa sering menggunakan smartphone. Sejalan dengan penelitian yang dilakukan Pollara \& Broussard (2011), Recent Pew Internet surveys show that more than $75 \%$ of students have cell phones in the United States and $90 \%$ of young adults (1829) are owners, which makes this number high among school-age people.

Maka berdasarkan hasil dari data tersebut dapat diartikan bahwa persepsi pada program studi pendidikan Biologi dengan program studi pendidikan matematika termasuk dalam kategori baik. Sejalan dengan hasil penelitian yang dilakukan Suartama (2018), bahwa hasil dan tanggapan proses belajar mengajar mahasiswa dengan menggunakan perangkat mobilelearning yang dikembangkan, produk tersebut dari segi kelayakan dapat dikatakan sangat baik dan memiliki tingkat interaktifitas yang baik serta mampu membuat mahasiswa aktif dalam proses pembelajaran. Menurut Pratama et al. (2013), mobile learning dihadirkan untuk mengatasi suatu permasalahan dalam kegiatan belajar, yang berguna dalam memfasilitasi, dan memberikan cara agar mahasiswa mampu memahami materi apa yang dijelaskan oleh dosen.

\section{SIMPULAN}

Berdasarkan hasil analisis data dari angket persepsi dan lembar wawancara yang dihasilkan dapat disimpulkan bahwa untuk persepsi program studi pendidikan Biologi dengan indeks level persepsi pada frekuensi sebanyak 17 mahasiswa dengan persentase sebesar 58.62\%. Selanjutnya, untuk program studi pendidikan Matematika frekuensi sebanyak 14 mahasiswa dengan persentase sebesar 50\%. Hasil penelitian dapat dikatakan bahwa penuntun praktikum fisika dasar II berbasis mobile learning dapat dikatakan dalam kategori baik. Selanjutnya, hasil dari wawancara sebagian besar mahasiswa menjawab positif dan 
disertai dengan berbagai alasan yang menginformasikan bahwa penggunaan media dapat mendukung aktivitas pembelajaran dan praktikum serta dapat memotivasi mahasiswa.

Saran pada penelitian ini ditujukan pada peneliti lain dan dosen. Pertama, untuk dosen diharapkan dengan hasil penelitian ini dapat dijadikan sebagai referensi untuk kedepannya dapat merancang penuntun praktikum fisika dasar II berbasis mobile learning. Kedua, diharapkan untuk penelitian yang lain dapat mengembangkan lembar observasi dan penuntun praktikum fisika dasar II berbasis mobile learning.

\section{DAFTAR RUJUKAN}

A. Limatahu, N., Aulia Rahman, N., Nur Abu, S. H., \& Cipta, I. (2017). Pengaruh Video Praktikum dengan Modul Elektronik terhadap Keterampilan Proses pada Materi Stoikiometri Siswa Kelas X SMAN 2 Tidore Kepulauan. Jurnal Pendidikan Kimia, 9(1), 225-228. https://doi.org/10.24114/jpkim.v9i1.6183

Adel Ali, R., \& Rafie Mohd Arshad, M. (2017). Investigating the Perception of Students Regarding M-Learning Concept in Egyptian Schools. International Journal of Interactive Mobile Technologies (IJIM), 11(6), 112.

Al-Hajri, R., Al-Sharhan, S., \& Al-Hunaiyyan, A. (2017). Students' Perceptions of Mobile Learning: Case Study of Kuwait. International Journal of Educational and Pedagogical Sciences, 11(2), 371-374.

Cahyanti, F. D., Sinaga, P., \& Amsor, N. A. (2018). Effectiveness of the New Generation E-Book Application for Mobile Phones in Improving the Conceptual Mastery of Kinematics. International Journal of Mobile Learning and Organisation, 13(2), 217. https://doi.org/10.1504/ijmlo.2019.10017848

Delialioğlu, Ö., \& Alioon, Y. (2014). Student Preferences for M-Learning Application Characteristics. International Conference Mobile Learning, (ii), 59-65.

Darmaji., Astalini., Rahayu, A., \& Maison (2018). Pengembangan Penuntun Praktikum Fisika Berbasis Keterampilan Proses Sains Menggunakan Model Problem Solving. Journal Edusains, 10(1).

Darmaji, D., Kurniawan, D. A., \& Suryani, A. (2019). Effectiveness of Basic Physics II Practicum Guidelines Based On Science Process Skills. JIPF (Jurnal Ilmu Pendidikan Fisika), 4(1), 1. https://doi.org/10.26737/jipf.v4i1.693

Edie, S. S., Masturi, Safitri, H. N., Alighiri, D., Susilawati, Sari, L. M. E. K., \& Iswari, R. S. (2018). The effect of using bomb calorimeter in improving science process skills of physics students. Journal of Physics: Conference Series, 983(1). https://doi.org/10.1088/1742-6596/983/1/012205

Foti, M. K., \& Mendez, J. (2014). Mobile Learning: How Students Use Mobile Devices to Support Learning. Journal of Literacy and Technology, 15(3), 58-78.

Hartini, R. F., Ibrohim., \& Qohar, A. (2018). Pemahaman Konsep dan Keterampilan Proses Sains melalui Inkuiri Terbimbing Berbasis Lingkungan pada Materi Ekosistem. Jurnal Pendidikan: Teori, Penelitian, dan Pengembangan, 3(9), 1168-1173.

Kurniawan, D. A., \& Parasdila, H. (2018). Description of Science Process Skills' Physics Education Students at Jambi University in Temperature and Heat Materials. Educational Review, USA, 2(9), 485-498. https://doi.org/10.26855/er.2018.09.004

Kustijono, R. (2018). the Effect of Scientific Attitudes Toward Science Process Skills in Basic Physics Practicum by Using Peer Model. International Journal of Geomate, 15(50), 82-87. https://doi.org/10.21660/2018.50.ijcst50

Maksum, I., Maliki, A., \& Hidayat, A. (2017). Topik Suhu dan Kalor melalui Pembelajaran Cognitive Apprenticeship. Jurnal Pendidikan: Teori, Penelitian, dan Pengembangan, 2(2), 304-308.

Mehdipour, Y., \& Zerehkahfi, H. (2013). Mobile Learning for Education: Benefits and Challenges. International Journal of Computational Enginering Research.

Misbah, M., Wati, M., Rif'at, M. F., \& Prastika, M. D. (2018). Pengembangan Petunjuk Praktikum Fisika Dasar I Berbasis 5M Untuk Melatih Keterampilan Proses Sains dan Karakter Wasaka. Jurnal Fisika Flux, 15(1), 26. https://doi.org/10.20527/flux.v15i1.4480

Ozdemir, G., \& Dikici, A. (2016). Relationships between Scientific Process Skills and Scientific Creativity: Mediating Role of Nature of Science Knowledge. Journal of Education in Science, Environment and Health, 3(1), 52-52. https://doi.org/10.21891/jeseh.275696

Fitriana, E., Utaya, S., \& Budijanto. (2016). Hubungan Persepsi Siswa tentang Proses Pembelajaran dengan Hasil Belajar Geografi di Homeschooling Sekolah Dolan Kota Malang. Jurnal Pendidikan: Teori, Penelitian, dan Pengembangan, 1(4), 662-667.

Pratama, R. A., Ulfa, S., \& Kuswandi, D. (2013). Mobile Learning Berbasis Game Based Learning Pelajaran Matematika Pokok Bahasan Bangun Ruang Sisi Datar. (2002), 1-8.

Pollara, P., \& Broussard, K. K. (2011). Student Perceptions of Mobile Learning : A Review of Current Research. Proceedings of Society for Information Technology @ Teacher Education International Conference 2011, 2011, 1643-1650.

Rahmawati., Handayanto, S. K., \& Dasna, I. W. (2018). Pengaruh Learning Cycle 5E terhadap Keterampilan Proses Sains Peserta Didik Kelas VIII. Jurnal Pendidikan: Teori, Penelitian, dan Pengembangan, 3(3), 286-290. 
Prawiradilaga., Ariani., \& Handoko. (2013). Mozaik Pendidikan E-Learning. Yogyakarta: Gava Media. Sarwono, J. (2006). Medote Penelitian Kuantitatif \& Kualitatif. Yogyakarta: Graha Ilmu.

Setiawan, A., Malik, A., Suhandi, A., \& Permanasari, A. (2018). Effect of Higher Order Thinking Laboratory on the Improvement of Critical and Creative Thinking Skills. IOP Conference Series: Materials Science and Engineering, 306(1). https://doi.org/10.1088/1757-899X/306/1/012008

Ślusarczyk, B. (2019). Industry 4.0 - Are We Ready? Polish Journal of Management Studies, 17(1), $232-248$. https://doi.org/10.17512/pjms.2018.17.1.19

Supurwoko, S., Cari, C., Sarwanto, S., Sukarmin, S., Budiharti, R., \& Dewi, T. S. (2018). Virtual Lab Experiment: Physics Educational Technology (PhET) Photo Electric Effect for Senior High School. International Journal of Science and Applied Science: Conference Series, 2(1), 381. https://doi.org/10.20961/ijsascs.v2i1.16750

Vyas, N., \& Nirban, V. (2014). Students' Perception on the Effectiveness of Mobile Learning in an Institutional Context. ELT Research Journal, 3(1), 26-36.

Yadaeni, A., Kusairi, S., \& Parno. (2018). Penguasaan Konsep dan Keterampilan Proses Sains Siswa Kelas XII pada Materi Fluida Statis. Jurnal Pendidikan: Teori, Penelitian, dan Pengembangan, 3(3), 357-364.

Yang, Q. F., Hwang, G. J., \& Sung, H. Y. (2018). Trends and Research Issues of Mobile Learning Studies in Physical Education: A Review of Academic Journal Publications. Interactive Learning Environments, O(0), 1-19. https://doi.org/10.1080/10494820.2018.1533478

Young, Hugh D., Freedman, Roger A., Sandin, T. R., \& Ford, A. Lewis.(2002). Fisika Universitas. Edisi Kesepuluh Jilid 1. Jakarta: Erlangga.

Zulika, A. M., Wijaya, M. H., Masitoh, U., Utari, S., \& Titin. (2018). Profil Keterampilan Proses Sains (KPS) Siswa dalam menggunakan Ragam Media Pembelajaran Gerak Melingkar di SMA. Jurnal Wahana Pendidikan Fisika, 3(1), 80-84. 